www.jmscr.igmpublication.org Impact Factor 5.244

Index Copernicus Value: 83.27 ISSN (e)-2347-176x ISSN (p) 2455-0450 crossref DOI: https://dx.doi.org/10.18535/jmscr/v5i1.22

Journal Of Medical Science And Clinical Research

\title{
Knowledge of Gestational Hypertension and Its Self Care Measures among Primigravid Women
}

\author{
Authors \\ Tanya Salim¹, Annamma Kuriakose ${ }^{2}$ \\ ${ }^{1}$ Associate Professor, O\&G Medical College Trivandrum \\ ${ }^{2}$ Lecturer, TMM College of Nursing \\ Email:drtanyasharmad@gmail.com
}

\begin{abstract}
Background: Hypertensive disorders in pregnancy is one of the major causes of maternal and perinatal morbidity and mortality. Though it cannnot the prevented, the adverse outcome can be prevented by early detection, proper monitoring, early detection of complications and timely decision making.

Aim: To asses the knowledge of gestational hypertension and knowledge regarding self care measures of gestational hypertension among primigravid women with gestational hypertension.

Materials and Methods: A descriptive study in a teritiary teaching centre. 240 primigravid women with gestational hypertension were included in the study.

Results: $70.7 \%$ of pregnant women had poor knowledge and only $4.2 \%$ had good knowledge regarding gestational hypertension. 36.4\% of pregnant women had poor knowledge and $26.4 \%$ had good knowledge regarding its self-care measures. Significant association was noted between knowledge of gestational hypertension and age and education of pregnant women. There is significant association of knowledge of self care measures of gestational hypertension with age,place of residence, educational status and use of mass media as a source of information.
\end{abstract}

Conclusion: Imparting health care information regarding gestational hypertension and its self care measures can go a long way in reducing the adverse outcomes in pregnant women with gestational hypertension.

Keywords: Gestational hypertension, primigravida, self-care.

\section{INTRODUCTION}

Hypertensive disorders in pregnancy is the most common medical disorder encountered during pregnancy and is one of the major causes of maternal and perinatal morbidity and mortality The incidence is $17 \%$ globally and $9 \%$ in India. It is a major cause of maternal mortality in Kerala second only to haemorrhage, and accounts for $12 \%$ maternal deaths. In India Gestational Hypertension continues to the responsible for the largest proportion of perinatal deaths resulting from prematurity and IUGR. Thus pregnancies complicated by hypertensive disorders are associated with increased risk of adverse maternal and perinatal outcome. Though hypertensive disorders in pregnancy cannot the prevented, its progress to severe can be arrested and development of complications can be prevented by early detection and quality antenatal care. The early recognition of elevated blood pressure in pregnancy and recognition of warning signs are of utmost importance in preventing the maternal and 
perinatal mortality and morbidity associated with hypertensive disorders in pregnancy.

The risk factors of gestational hypertension include primigravid, elderly and teenage pregnancy, obesity, low socioecnomic status, diabetes, renal disease, connective tissue disorders, thrombophillias, molar pregnancy and multiple gestation among others. Signs of impending eclampsia include sudden rise in blood pressure, decreased urine output, generalised odema, proteinuria, headache, visual disturbances, epigastric pain, impaired liver function, nausea and vomiting. Development of IUGR is also an indicator of severity.

The care of a woman with gestational hypertension should include regular antenal visits with proper maternal and fetal monitoring which includes blood pressure and weight monitoring, urinary protein analysis, abdominal examination, fetal assessment, laboratory studies, antihypertensive therapy and advise regarding rest, diet and warning signs. Therefore in a developing country like India, the woman's knowledge regarding the condition, its warning signs and need for regular monitoring and medication can go a long way towards reducing the morbidity and mortality associated with it.

\section{Materials and Methods}

A descriptive study was carried out in SAT Hospital, Thiruvananthapuram which is a teritiary care teaching institution. 240 primigravid women diagnosed with gestational hypertension were included in the study by a consecutive sampling technique. A semi structured interview schedule was used to collect data from the patients. This interview schedule included two parts. Part I for sociodemographic data and Part II which included questions to assess the knowledge of pregnant women regarding gestational hypertension and its self care measures. It included 2 sections.

Section A: Knowledge of pregnant woman regarding gestational hypertension which include questions relating to definition, risk factors and clinical manifestations.
Section B: Knowledge regarding self care measures which included questions related to rest and sleep, dietary modifications, frequent antenatal check up, maternal and fetal monitoring, regular medication and preventive measures.

The data collection was done for a period of six weeks from January $19^{\text {th }} 2015$ to February $21^{\text {st }}$ 2015. Data was collected after a brief self explanation session and taking a consent. It look 20 - 30 minutes for each interview and after the interview, the investigator explained about gestational hypertension and its self care measures and clarified their doubts.

\section{Statistical Analysis}

Data was assessed by SPSS version 16. The data was grouped into four as related to demographic variables, knowledge of gestational HT and knowledge of self care and association of demographic factors with knowledge of gestateonal hypertension and its self-care measures. The sociodemographic variables and knowledge scores were summarised by frequency and percentage. Association between knowledge and selected demographic variable was done by Chi square test. The data was analysed by descriptive and inferential statistics.

\section{Result}

Among the 240 pregnant women in the study, $37.7 \%$ of the women belonged to the age group $<21$ years and only $8.4 \%$ belonged to age group $>35$ years. Majority $(75.7 \%)$ of women were residing in rural area. $88 \%$ were unemployed $70.3 \%$ of these women belonged to low socio economic status. None of the women were illiterate $18.8 \%$ had primary education, $27.2 \%$ had high school education, $22.2 \%$ had higher secondary education while $23 \%$ were graduates. The study showed that pregnant women get their health information from multiple sources- parents, friends and relatives $(87.9 \%)$ health personnel (72.4\%) and mass media (41\%). 3.3\% of women did not have any information. 


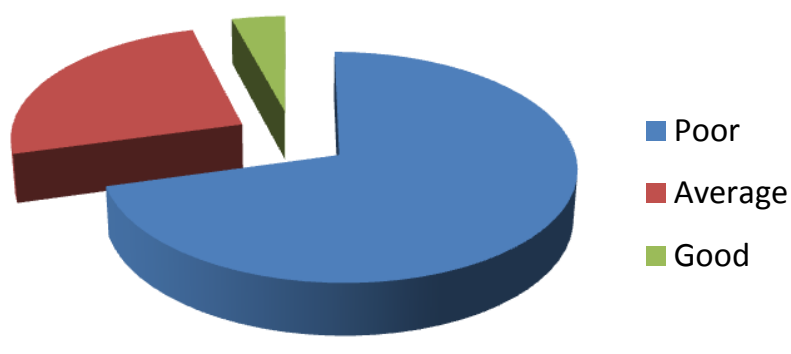

In the study population, it was noted that $70.7 \%$ of pregnant women had poor knowledge, $25.1 \%$ had average knowledge and $4.2 \%$ had good knowledge regarding gestational hypertension

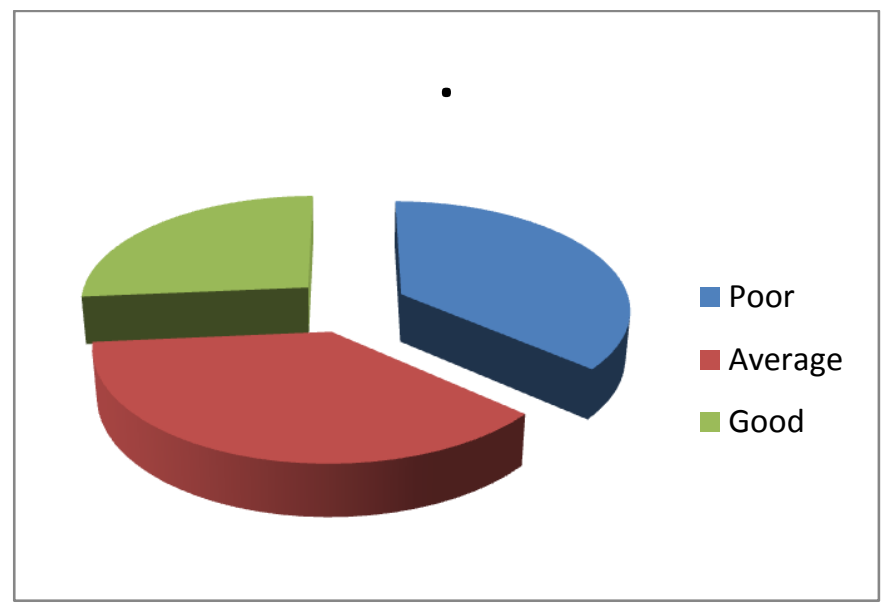

Regarding knowledge about self care measures of gestational hypertension $36.4 \%$ of pregnant women had poor knowledge, $37.2 \%$ had average knowledge and $26.4 \%$ had good knowledge.

On assessing the association of knowledge regarding gestational hypertension with socio demographic variables (Table $1 \& 2$ ), it was seen that there is significant association of knowledge with age of the pregnant women. None of the women <21 years of age had good knowledge, while $20 \%$ of women in the 31-35 age group had good knowledge regarding gestational hypertension. There was significant association of knowledge regarding gestational hypertension with education of pregnant woman. As the level of education increases, knowledge also improved. This study found no significant association of knowledge regarding gestational hypertension with place of residence, socio economic status, occupation or source of health information.

Association of knowledge of self care measures of gestational hypertension with demographic variables (Table $3,4,5, \& 6$ ), there was found to be significant association of knowledge of self care measures with age of the woman. Among younger women $<21$ years of age only $16.7 \%$ had good knowledge while among women aged 31-35 years $54.2 \%$ had good knowledge regarding self care measures. Rural women had better knowledge of self care measures. $28.7 \%$ having good knowledge compared to the urban women of whom only $19 \%$ had good knowledge. This was found to be significant statistically. There was a strong association between knowledge of self care measures and level of education. Among women with primary education, only $6.7 \%$ had good knowledge. This increased with the level of education and among graduates there were $56.4 \%$ with good knowledge, $43.6 \%$ with moderate knowledge and none with poor knowledge. The employed women had a better knowledge of self care measures compared to the unemployed. Only $9.7 \%$ of the employed had a poor knowledge compared to $40.4 \%$ of the unemployed. While considering the source of health information in these women, women who had their information from mass media had better level of knowledge. There was no association of knowledge of self care measures of gestational hypertension with other source of health information. The study found no significant association of knowledge of self care measures with socio economic status of the women. 


\section{JMSCR Vol||05||Issue||01||Page 15328-15335||January}

Table 1

\begin{tabular}{|c|c|c|c|c|c|c|c|c|c|c|}
\hline \multirow{3}{*}{$\begin{array}{l}\text { Age } \\
\text { In } \\
\text { Years }\end{array}$} & \multicolumn{8}{|c|}{ knowledge regarding GHTN } & \multirow[t]{2}{*}{$\mathbf{X}^{2}$} & \multirow[t]{2}{*}{$\mathbf{P}$} \\
\hline & \multicolumn{2}{|c|}{ Poor } & \multicolumn{2}{|c|}{ average } & \multicolumn{2}{|c|}{ Good } & \multicolumn{2}{|c|}{ Total } & & \\
\hline & $\mathbf{N}$ & $\%$ & $\mathbf{N}$ & $\%$ & $\mathbf{N}$ & $\%$ & $\mathbf{N}$ & $\%$ & 16.135 & 0.003 \\
\hline$<21$ & 73 & 81.1 & 17 & 18.9 & 0 & 0 & 9 & 100 & & $<0.01$ \\
\hline $21-25$ & 39 & 62.9 & 21 & 33.9 & 2 & 3.2 & 62 & 100 & & \\
\hline $26-30$ & 35 & 79.1 & 9 & 20.9 & 0 & 0 & 44 & 100 & & \\
\hline $31-35$ & 14 & 58.3 & 5 & 20.8 & 5 & 20.8 & 24 & 100 & & \\
\hline$>35$ & 9 & 45 & 8 & 40 & 3 & 15 & 20 & 100 & & \\
\hline Total & 170 & 70.7 & 60 & 25.1 & 10 & 4.2 & 240 & 100 & & \\
\hline
\end{tabular}

$\mathrm{P}$ value significant at 0.05

Table 2

\begin{tabular}{|c|c|c|c|c|c|c|c|c|c|c|}
\hline \multicolumn{2}{|c|}{ Education } & \multicolumn{7}{|c|}{ Knowledge regarding GHTN } & \multirow{2}{*}{$\begin{array}{l}\mathbf{X}^{2} \\
52.593\end{array}$} & \multirow{2}{*}{$\begin{array}{c}\mathbf{P} \\
<0.001\end{array}$} \\
\hline Primary & 42 & 93.3 & 3 & 6.7 & 0 & 0 & 45 & 100 & & \\
\hline $\begin{array}{l}\text { High } \\
\text { school }\end{array}$ & 57 & 87.7 & 8 & 12.3 & 0 & 0 & 65 & 100 & & \\
\hline Higher & 30 & 56.6 & 23 & 43.4 & 0 & 0 & 53 & 100 & & \\
\hline \multicolumn{11}{|c|}{ Secondary } \\
\hline Diploma & 19 & 85.7 & 3 & 14.3 & 0 & 0 & 22 & 100 & & \\
\hline Degree & 22 & 40 & 23 & 41.8 & 10 & 18.2 & 55 & 100 & & \\
\hline Total & 170 & 70.7 & 60 & 25.1 & 10 & 4.2 & 240 & 100 & & \\
\hline
\end{tabular}




\section{JMSCR Vol||05||Issue||01||Page 15328-15335||January}

Table 3

\begin{tabular}{|c|c|c|c|c|c|c|c|c|c|c|}
\hline \multicolumn{6}{|c|}{$P$ value significant at 0.05} & \multicolumn{5}{|c|}{$P$ value $<0.01$} \\
\hline \multirow[t]{3}{*}{ Place } & \multicolumn{5}{|c|}{ Knowledge regarding Self care } & \multicolumn{2}{|c|}{ Total } & \multirow{2}{*}{\multicolumn{2}{|c|}{$\mathbf{X}^{2}$}} & \multirow[t]{2}{*}{$\mathbf{P}$} \\
\hline & Poor & & Aver & & Good & & & & & \\
\hline & $\mathrm{N}$ & $\%$ & $\mathrm{~N}$ & $\%$ & $\mathrm{~N}$ & $\%$ & $\mathrm{~N}$ & $\%$ & 6.962 & 0.031 \\
\hline Rural & 71 & 38.7 & 59 & 32.6 & 52 & 28.7 & 182 & 100 & & \\
\hline Urban 17 & 29.3 & 30 & 51.7 & 11 & 19 & 58 & 100 & & & \\
\hline Total & 88 & 36.4 & 89 & 37.2 & 63 & 26.4 & 240 & 100 & & \\
\hline
\end{tabular}

$P$ value significant at 0.05

Table shows that, $\mathrm{P}$ value is $<0.05$

Table 4

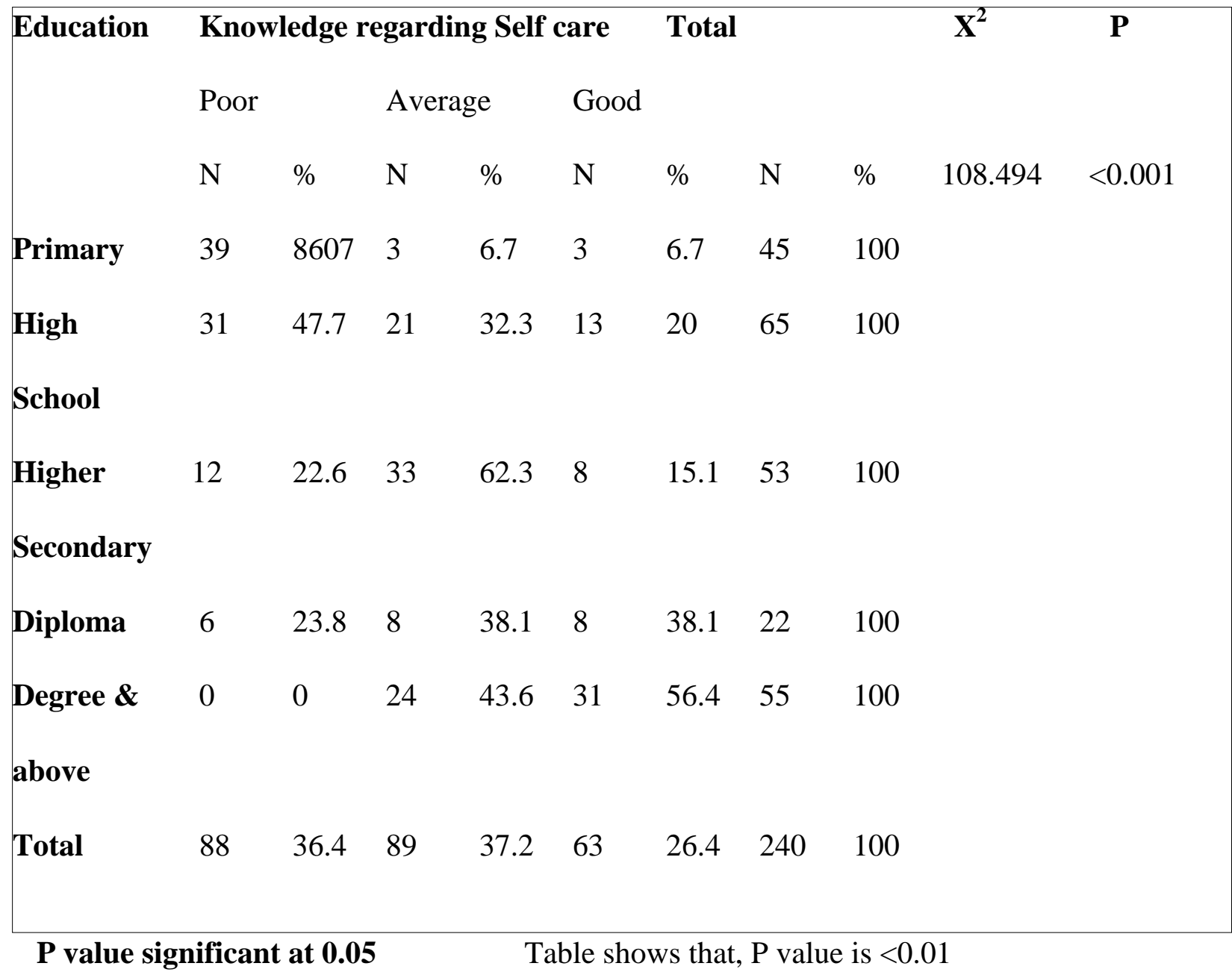


Table 5

\begin{tabular}{|lcccccccccccc|}
\hline Occupation & \multicolumn{8}{c}{ Knowledge regarding Self care } & Total & & $\mathbf{X}^{2}$ & P \\
& Poor & \multicolumn{2}{c|}{ Average } & Good & & & & & \\
& $\mathrm{N}$ & $\%$ & $\mathrm{~N}$ & $\%$ & $\mathrm{~N}$ & $\%$ & $\mathrm{~N}$ & $\%$ & 11.0 & 0.004 \\
& & & & & & & & & & & \\
Unemployed & 84 & 40.4 & 72 & 34.6 & 52 & 25 & 208 & 100 & & \\
Employed & 4 & 9.7 & 17 & 54.8 & 11 & 35.5 & 32 & 100 & & \\
Total & 88 & 36.4 & 89 & 37.2 & 63 & 26.4 & 240 & 100 & & \\
\hline
\end{tabular}

$P$ value significant at 0.05

Table shows that, $\mathrm{P}$ value is $<0.01$

\section{Table 6}

\begin{tabular}{|c|c|c|c|c|c|c|c|c|c|c|}
\hline Source of & Kno & ledge & egar & g Self & are & Total & & & $\mathbf{X}^{2}$ & $\mathbf{P}$ \\
\hline Informatio & Poor & & $\mathrm{Av}$ & & Good & & & & & \\
\hline & $\mathrm{N}$ & $\%$ & $\mathrm{~N}$ & $\%$ & $\mathrm{~N}$ & $\%$ & $\mathrm{~N}$ & $\%$ & & \\
\hline $\begin{array}{l}\text { Health } \\
\text { personnel }\end{array}$ & 65 & 37.6 & 67 & 38.7 & 41 & 23.7 & 173 & 100 & 2.291 & 0.318 \\
\hline Parents/ & 73 & 34.8 & 80 & 38.1 & 57 & 27.1 & 210 & 100 & 2.022 & 0.364 \\
\hline Friends/ & & & & & & & & & & \\
\hline Relative & & & & & & & & & & \\
\hline $\begin{array}{l}\text { Mass } \\
\text { media }\end{array}$ & 20 & 20.4 & 46 & 46.9 & 32 & 32.7 & 98 & 100 & 18.36 & $<0.01$ \\
\hline
\end{tabular}

\section{Discussion}

The study included only primigravid women, as a pilot study conducted in our institution showed that multigravid women had a reasonably good knowledge regarding gestational hypertension and its self care measures as most of them had gestational hypertension in the previous pregnancy. This was supported by a study by Prathima P, comparing the knowledge between primi and multigravid women ${ }^{1}$. Based on this study $70.2 \%$ pregnant women had poor knowledge regarding gestational hypertension and $36.9 \%$ had poor knowledge regarding its self care measures. This was similar to the findings of Helewa $\mathrm{M}^{2}$, where in a sample of 70 primigravid women, $95 \%$ were unaware of gestational hypertension and its self care measures. Another study by Jayashree in Bangalalcot found that $74 \%$ had poor knowledge regarding gestational hypertension and $36.9 \%$ had poor knowledge of 
self care measures ${ }^{3}$.Among 240 women, 37.7\% belong to age group <21years. Several studies have showed the incidence to the higher among teenage pregnancies and also in advanced maternal age ${ }^{4,5} .75 .7 \%$ of the pregnant women, in my study lived in the rural area, $27.2 \%$ had high school education, $88 \%$ were house wives, and $70.3 \%$ were BPL. A study conducted in JJ Group of Government Hospitals, Mumbai showed that incidence of PIH was higher among urban women, women with low socioeconomic status, low educational status and unemployed women ${ }^{6}$. Studies by Mehul T et al ${ }^{7}$ and Marialda Martis et al ${ }^{8}$ also showed incidence of gestational hypertension to the higher in women belonging to low socioeconomic status. In the present study, women get health information from multiple sources namely parents, friends, relatives, mass media and health personnel. This was agreed by Jayashree et al ${ }^{2}$.

This study showed that there is significant association of knowledge regarding gestational hypertension with age and education of pregnant women. There is significant association of knowledge of self care measures of gestational hypertension with age, place of residence, education, occupation and mass media as a source of health information. A study by Namitha in Mangalore also supported these findings 9 .

Knowledge improved with age and level of education. Employed women had and better knowledge, than unemployed and women who received their knowledge from mass media had a better awareness regarding self care measures.

Even in our state Kerala, which boasts of a $100 \%$ literacy rate and higher health care indices compared to the rest of India, the knowledge of gestational hypertension and its self care measures is not up to the mark. This may be responsible for the increase in incidence of severe cases and increase in associated morbidity and mortality. Even though gestational hypertension cannot the prevented, improving the knowledge of pregnant women by health care talks by health personnel in the hospital and public awareness programmes and also through mass media can go a long way towards reducing the burden of the disease in the society.

\section{Conclusion}

On the basis of findings of this study it can be concluded that pregnant women with gestational hypertension have poor knowledge about gestational hypertension and average knowledge about self care measures of gestational hypertension. Under these circumstances, pregnant women need more health educational programmes about gestational hypertension and its self care measures. Periodic awareness programmes may be organised, health education programmes can be conducted in antenatal OPD and wards in the hospital and an information booklet may be prepared and distributed to pregnant women regarding gestational hypertension and its self care measures.

\section{Acknowledgement}

Our sincere thanks to Dr Nirmala C, and NURSING Professor obstetrics gynecology SATH and Mrs. Nirmala L Principal, Government College of Nursing

\section{References}

1. Prathima P .Compare knowledge on selfcare management of PIH between primigravida and multigravida-NUJHS Vol 4, No: 3, September 2014 ISSN 2249-7110

2. Helewa M, Heaman M, Robinson M A. Community based home care program for the management of pre eclampsia. Canadian medical association journal. September 2005; 149. 121-25.

3. Jayashree $M$ A: Pregnancy induced hypertension among antematal mothers. NNT 2013 August; 9(5); 37-40

4. Bangal V, Giri P, Mahajan A. Maternal and foetal outcome in pregnancy induced hypertension: a study from rural tertiary care teaching hospital in India. IJBR 2011; 2(12:595-599. 
5. Lamminpaa $\mathrm{R}$ et al. Preeclampsia complicated by advanced maternal age: a registry-based study on primiparous women in Finland 1997-2008. BMC Pregnancy Childbirth 2012; 12(1): 47.

6. Shahid A. Mujawar and Vinayak W. Patil Socio-economic characteristics and pregnancy induced hypertension in the women of western region of India. Internat. J. Med.Sci. 2012 Aug; 3(1\&2): 24-269.

7. Mehul $\mathrm{T}$ Parmer, Harsha M Solanki, Vibha V Goasalia: Study of risk factors of perinatal death in Pregnancy Induced Hypertension: National Journal of Community Medicine 2012 Oct - Dec; 3(4). P. 705. Available from www.njcmindia.org

8. Marialda Martins, Marisa Monticelli, Odalea Maria Bruggemann, Roberta Costa. The production of knowledge regarding gestational hypertension in the stricto sensu graduate nursing studies in Brazil: Rev. Esc. Enferm. USP; 46(4)

2012 Aug. Available from http://dx.doi.org/10.1590/SOO8062342012000400003.

9. Namitha Jose, Sudha A Raddi, Sangeeta Khardhe .Knowledge regarding preecclampsia and self-care measures among pregnant women-SAFOG 2010 MayAugust;2;157-162. 